\title{
A Novel Optimization based Hybrid Power Filter for Current Harmonic Mitigation
}

\author{
Vivek Kumar Lahare, B. Chiranjeecv Rao², Vishnu Kumar Sahu ${ }^{3}$ \\ ${ }^{1}$ M.tech Student, Dept. of Electrical and Electronics Engineering, SSGI SSTC Bhilai (C.G.), India \\ ${ }^{2}$ Assistant Professor, Dept. of Electrical and Electronics Engineering, SSGI SSTC Bhilai (C.G.), India \\ ${ }^{3}$ Assistant Professor, Dept. of Electrical Engineering, SSGI SSTC Bhilai (C.G.), India
}

\begin{abstract}
This paper work deals with elimination of harmonics using shunt active power filter. Active power filters are widely used for reduction of harmonics in power system caused by nonlinear loads. The reference current is determined for compensation of harmonics source current with help of synchronous reference frame (SRF) method.

Conventional PI controller is implemented in the system and compensated reference current is generated by IRPT theory. Shunt Active Power Filter is mainly used to minimize the harmonics in the power system feeding non linear load. The proposed system is implemented with GSA. This paper shows the application of the proposed method for harmonic elimination under different load condition, simulations are done using MATLAB.
\end{abstract}

Key Words: Shunt Active Power Filter (SAPF), Proportional controller (PI), Power quality (PQ), Synchronous Reference Frame Theory (SRF), Total Harmonics Distortion (THD), Hybrid filter (HF).

\section{INTRODUCTION}

The distortion of current and voltage due to the presence of harmonics, due to the equipment of the energy system which is connected to maintain a stable and reliable energy flow in the energy system. The main effects include overheating, vibration and resonance problems, low power factor, overload, capacitor failure, reduced efficiency, communication failure, and power fluctuations. The harmonic can be considered as a pollutant polluting the entire energy system. Therefore, it is necessary to develop and implement a solution to improve the quality of energy in the power supply system. To resolve these problems, active power filters are introduced into the power systems and, therefore, many compensation algorithms have been reported to drive the APF control. Here, a compensation technique based on a synchronous reference frame (SRF) is used to extract the SAPF reference stream. This methodology requires information on a variable, namely the current of the charging terminal. In this document, the simulation based on DSTATCOM MATALAB is carried out using the synchronous reference theory for reactive power compensation, inbalance, reduction of total harmonic distortion (THD) and improvement of power factor of the system.

\subsection{State of the Art on Hybrid Power Filters}

The power filter technology is now a mature technology to compensate for the different types of non-linear loads through current based compensation and to improve the quality of the AC power supply Voltage-based compensation techniques that eliminate voltage harmonics, sags, swell, notches, glitches, spikes, flickers ,and voltage imbalance and provide voltage regulation. In addition, these filters are also

identified by the nature of non-linear loads, such as loads supplied with voltage (rigid voltage or voltage source on the DC side of the rectifier through the capacitive filter), the loads driven by the current (rigid current or power source on the DC side of the DC motor controller or power source for the AC motor controller powered by CSI), and a combination of the two. Different topologies such as passive, active and bypass hybrid filters, series, and a combination of the two configurations for single-phase two-wire, three-phase threewire and three-phase It has been proposed to use four-wire systems which use current and voltage source converters Improve the quality of current in the AC network. As mentioned earlier, hybrid filters are cost effective and Perfect solution for non-linear load compensation and to provide clean AC power and ideal for different charges. This section describes the chronological development and current state of the HF Technology

\subsection{Classification of Hybrid Power Filters}

HPFs can be classified according to the number of elements in the topology, the supply system and the type converter used in its circuits.

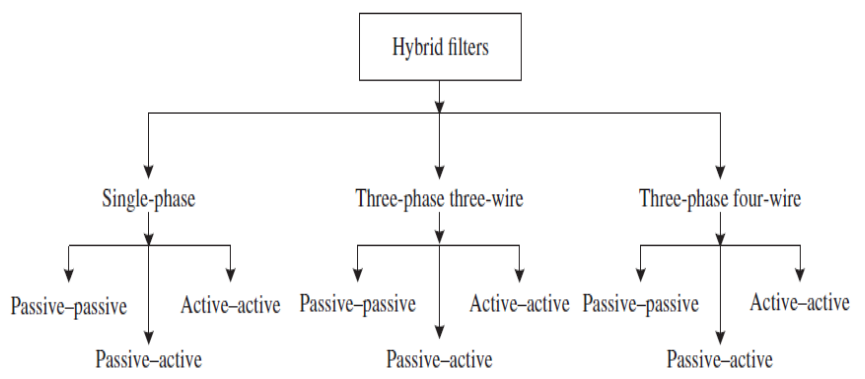

Figure 1: Classification of hybrid filters power filter

The power system can be single-phase two-wire, three-phase three-wire, or a three-phase four-wire system to power various non-linear loads. The converter can be a VSC or a CSC to perform the APF part of the hybrid power filter with appropriate control. 


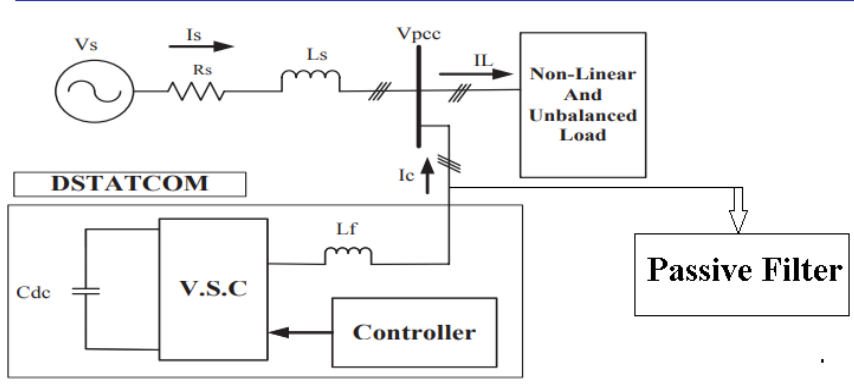

Active Filter

Figure2. Block diagram of Shunt Active Shunt Passive Hybrid filter

\subsection{Principle of Operation of Hybrid Power Filters}

The main goal of HPF is to reduce the nonlinear load and / or multiple power quality issues of the power system. A hybrid power filter reduces most power quality problems for satisfactory operation of consumer equipment, even in the case of a contaminated power system. At the same time, it reduces most voltage-based power quality problems, such as voltage harmonics, imbalance, senescence and swelling, and currentbased power quality problems, such as harmonics current, reactive power, unbalanced currents. , Provides loads and / or neutral current and power fluctuations present in the power system, and symmetrical sinusoidal currents in the power supply, regulating the DC bus voltage at best as a combination of two VSCs universally coordinate with serial filters in active filters. [7].

\subsection{Control of a Hybrid Filter Using Instantaneous Reactive Power Theory}

In the hybrid filter configuration shown in Figure 1, threephase supply currents are sensed and their harmonic Figure 3: Instantaneous reactive power theory control algorithm for the active filter element of the hybrid filter

Contents are estimated using the IRPT algorithm adopted for the conventional active filter as shown in Figure 2. But, instead of load currents, supply currents are sensed and processed using the IRPT-based control algorithm.

The three-phase filtered supply voltages are transformed into two-phase $\alpha-\beta$ orthogonal coordinates $\left(v_{\mathrm{s} \alpha} ; v_{\mathrm{s} \beta}\right)$

$$
\left(\begin{array}{c}
v_{\mathrm{s} \alpha} \\
v_{\mathrm{s} \beta}
\end{array}\right)=\sqrt{\frac{2}{3}}\left(\begin{array}{ccc}
1 & -\frac{1}{2} & -\frac{1}{2} \\
0 & \frac{\sqrt{3}}{2} & -\frac{\sqrt{3}}{2}
\end{array}\right)\left(\begin{array}{c}
v_{\mathrm{sa}} \\
v_{\mathrm{sb}} \\
v_{\mathrm{sc}}
\end{array}\right) .
$$

These three-phase filtered load current are transformed into two-phase $\alpha-\beta$ orthogonal coordinates (Is $\alpha$, Is $\left._{\beta}\right)$ as

$$
\left(\begin{array}{c}
i_{\mathrm{s} \alpha} \\
i_{\mathrm{s} \beta}
\end{array}\right)=\sqrt{\frac{2}{3}}\left(\begin{array}{ccc}
1 & -\frac{1}{2} & -\frac{1}{2} \\
0 & \frac{\sqrt{3}}{2} & -\frac{\sqrt{3}}{2}
\end{array}\right)\left(\begin{array}{l}
i_{\mathrm{sa}} \\
i_{\mathrm{sb}} \\
i_{\mathrm{sc}}
\end{array}\right) .
$$

From these two sets of expressions, the instantaneous active power $p$ s and the instantaneous reactive power $q$ s flowing from the supply side are calculated as

$$
\left(\begin{array}{c}
p_{\mathrm{s}} \\
q_{\mathrm{s}}
\end{array}\right)=\left(\begin{array}{cc}
v_{\mathrm{s} \alpha} & v_{\mathrm{s} \beta} \\
v_{\mathrm{s} \beta} & -v_{\mathrm{s} \alpha}
\end{array}\right)\left(\begin{array}{c}
i_{\mathrm{s} \alpha} \\
i_{\mathrm{s} \beta}
\end{array}\right) .
$$

Let and $\mathrm{q}_{\mathrm{s}}$ be the DC component and the AC element of $\mathrm{p}_{\mathrm{s}}$, respectively and $\mathrm{q}_{\mathrm{s}}$ and $\mathrm{q}_{\mathrm{s}}$ be the DC component and the $\mathrm{q}_{\mathrm{s}}$ AC element, alternately.

$$
p_{\mathrm{s}}=\bar{p}_{\mathrm{s}}+\tilde{p}_{\mathrm{s}}, \quad q_{\mathrm{s}}=\bar{q}_{\mathrm{s}}+\tilde{q}_{\mathrm{s}} .
$$

In these expressions, the fundamental load power is transformed to DC components $p \mathrm{~s}$ and $q \mathrm{~s}$, and the distortion or negative sequence is transformed to AC components $\sim p$ s and $\sim q \mathrm{~s}$. The DC components of active and reactive powers are extracted by using two high-pass filters. In addition, the active filter regulates its DC capacitor voltage without any external power supply. If the active filter outputs a fundamental voltage that is in phase with the fundamental leading current of the passive filter, then the active power formed by the leading current and the fundamental voltage is supplied to the DC capacitor. Therefore, the electrical quantity to be controlled in the DC voltage of the AF feedback loop is added to the reactive power $(\sim q \mathrm{~s})$. For the buildup of the DC bus voltage of the AF, the error between the sensed DC bus voltage and the reference DC bus voltage is given to a PI controller. The output of the PI controller is added to the AC component of instantaneous reactive power. Hence, the reference powers for the harmonic currents are estimated as

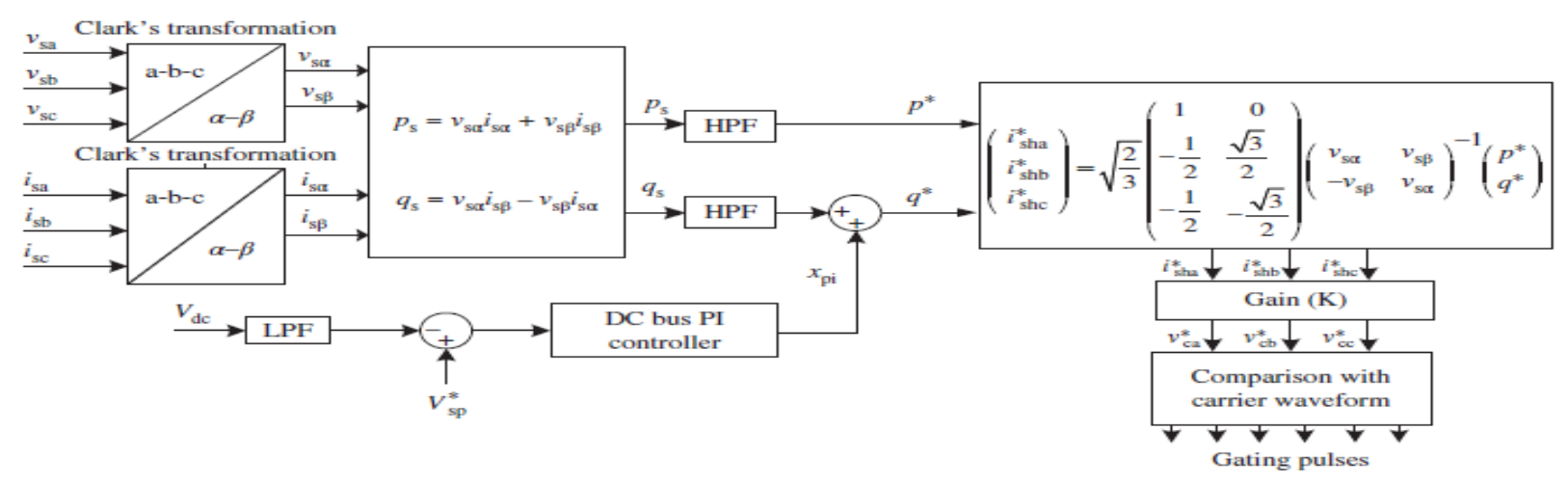




$$
\begin{aligned}
& p^{*}=\tilde{p}_{\mathrm{L}}, \\
& q^{*}=\tilde{q}_{\mathrm{L}}+x_{\mathrm{pi}},
\end{aligned}
$$

Where $x_{\mathrm{pi}}$ is the output signal from the PI controller. Here, a low-pass filter is also used in the DC bus voltage feedback loop to eliminate high-frequency ripples in DC bus voltages.

The reference three-phase harmonic currents $\left(i^{*}{ }_{\text {sha }} ; i^{*}{ }_{\text {shb }} ; i^{*}{ }_{\text {shc }}\right)$ are estimated as

$$
\left(\begin{array}{c}
i_{\mathrm{sha}}^{*} \\
i_{\mathrm{shb}}^{*} \\
i_{\mathrm{shc}}^{*}
\end{array}\right)=\sqrt{\frac{2}{3}}\left(\begin{array}{cc}
1 & 0 \\
-\frac{1}{2} & \frac{\sqrt{3}}{2} \\
-\frac{1}{2} & -\frac{\sqrt{3}}{2}
\end{array}\right)\left(\begin{array}{cc}
v_{\mathrm{s} \alpha} & v_{\mathrm{s} \beta} \\
-v_{\mathrm{s} \beta} & v_{\mathrm{s} \alpha}
\end{array}\right)^{-1}\left(\begin{array}{c}
p^{*} \\
q^{*}
\end{array}\right)
$$

The estimated harmonic current in each phase is amplified by a gain $K$ and given as input to a PWM controller as a reference voltage $V^{*}{ }_{\mathrm{c}} . K I_{\mathrm{sh}}$. The gating signals are generated by comparing the reference voltage $V^{*}$ with a triangle wave carrier frequency. This induces a voltage in series with the three-phase passive filter, thus improving the performance of the passive filter alone, as explained in the compensation principle of a hybrid filter

\section{GRAVITATIONAL SEARCH OPTIMIZATION}

GSA is an optimization method which designed to base on Newtonian gravity and the laws of motion. In this algorithm, agents are considered as objects and their performance is measured by their masses [1]. All of the masses in the search space are attracted each other according to Newtonian gravity laws and the masses which exposed the force of gravity reach optimum solution by acting in search space. This movement of the masses takes place according to Newton's second law of motion. During the algorithm, this is the heaviest mass moves slower than the other masses and attracts others. When the stop criterion is reached, the optimum solution of the problem would be reached with the greatest mass.

\section{PI CONTROLLER}

In control systems, it is very important to obtain controller parameters that make the system stable. One of the methods used to obtain these parameters is the SBL method. The SBL method is a graphical method used to determine the controller parameters that make the control system stable. The choice of the suitable controller type is crucial to achieve the desired design criteria. In most applications, simple structured controllers are preferred. PID controllers are often preferred by the industry for reasons such as simple strucsture and robust performance characteristics. The optimization process can be defined as selecting the most appropriate one from the current situations. Simulink models have been developed for optimizations based on the integral performance criteria. The optimization process begins by entering initial values in controller parameters. When the smallest error value is reached, the optimization stops and the most suitable controller parameters are obtained

Now here to tuned the parameter of PI controller IAE, ISE and ITAE criteria are used.

$$
\begin{aligned}
& \text { 1. IAE }=\int|e(t)| d t \\
& \text { 2. ISE }=\int e^{2}(t) d t \\
& \text { 3. ITAE }=\int t\left|e^{2}(t)\right| d t
\end{aligned}
$$

\section{BLOCK DIAGRAM OF HYBRID FILTER AS A COMBINATION OF ACTIVE SHUNT AND PASSIVE SHUNT FILTER}

The basic circuit configuration of the line with compensation is as shown in figure 4 . The active filter is connected in shunt with shunt connected passive filter. The MATLAB/SIMULINK is carried out with the control strategy of instantaneous reactive power theory, which is same as that of series active and passive shunt hybrid filter configuration. The gating pulses for VSI is provided by the comparison of source current and reference current with the rectangular pulse generator. Hybrid filters are usually considered a cost-effective option for power quality improvement, compensation of the poor power quality effects due to nonlinear loads, or to provide a sinusoidal AC supply to sensitive loads.

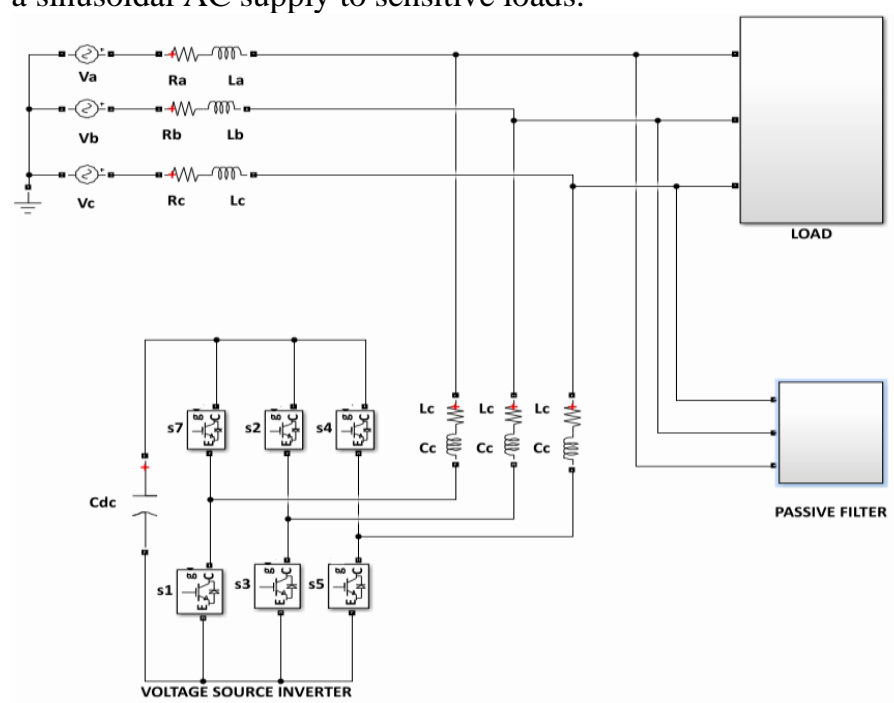

Figure 4: Line Diagram of the system with Shunt Active and Shunt Passive Filter compensation

\section{SIMULATION AND RESULTS}

Result is simulated in MATLAB/Simulink toolbox to check the system behavior and performance. The system is simulated under nonlinear load configuration for which the approach of Gravitational Search Algorithm controller based Shunt Active Shunt Passive Hybrid Filter. The main objective is to minimize the odd harmonic components using Gravitational Search Algorithm technique.

The source current without compensation is given in figure 5. Since there is no compensation provided the load current waveform is exactly as source current waveform. It can be seen that the source current contains harmonic content and thus is not purely sinusoidal. 


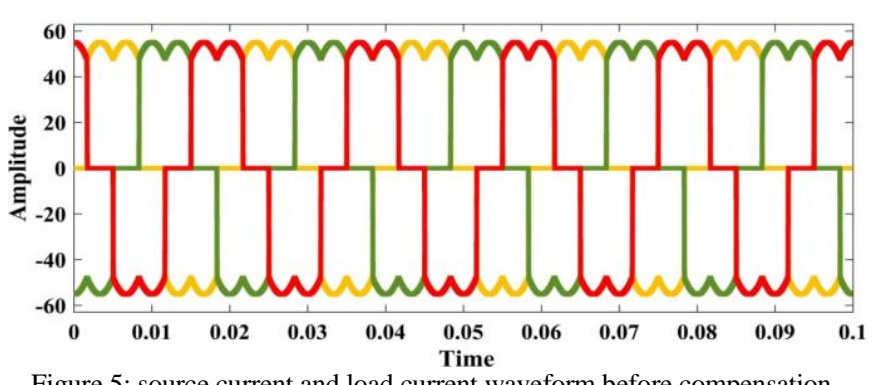

Figure 5: source current and load current waveform before compensation

Figure 5 shows the waveform of source Current and load current when Hybrid Filter is not connected in the system for filtering the harmonic current components which can be produced due to nonlinear load. From the above figure it is clear that the harmonic in current is produced by the connected nonlinear loads. It is cleared that in above figure source current is non-sinusoidal thus power factor will reduced and power loss will increase in the system. It also affects the stability of source side of the system. The source current contains $12.34 \%$ THD when compensation is not provided which is above IEEE 5191992 standard along with a fundamental current of 23.29A. The FFT analysis is given in fig 6

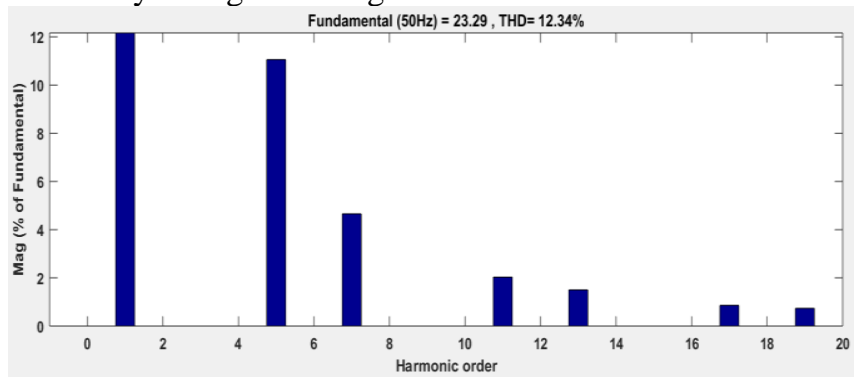

Figure 6: FFT analysis of source current without compensation

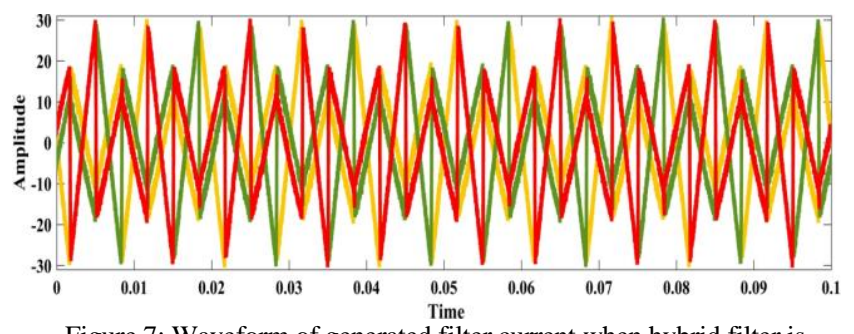

Figure 7: Waveform of generated filter current when hybrid filter is connected

Figure 7 shows the waveform of generated filter current to compensate harmonic current which can be produced by the nonlinear load. This filter current is injected at the Point of Common Coupling (PCC) to mitigate Total Harmonic Distortion (THD) of the system. This filter current is equal and opposite in magnitude with respect to the harmonic current which is generated by the nonlinear load.

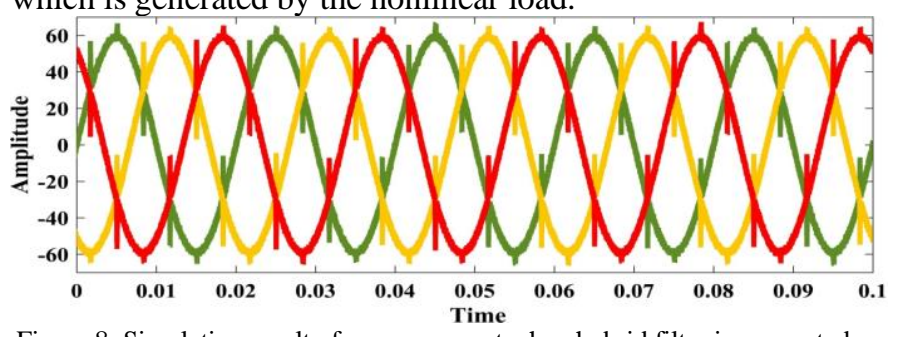

Figure 8: Simulation result of source current when hybrid filter is connected
Fig 8 shows waveform of compensated current, from above fig. 5.8 it is clear that the when hybrid filter connected in the system, then it injects compensated current which is equal and opposite of harmonics components due to nonlinear load in the system. The waveform has improved when hybrid filter is switched ON and the waveform of source current has become more close to sinusoidal than before compensation. The capacitor charging voltage $(\mathrm{Vdc})$ which generates required current with harmonics for the compensation of reactive power is shown in figure 9. The capacitor initial charging voltage is $150 \mathrm{~V}$.

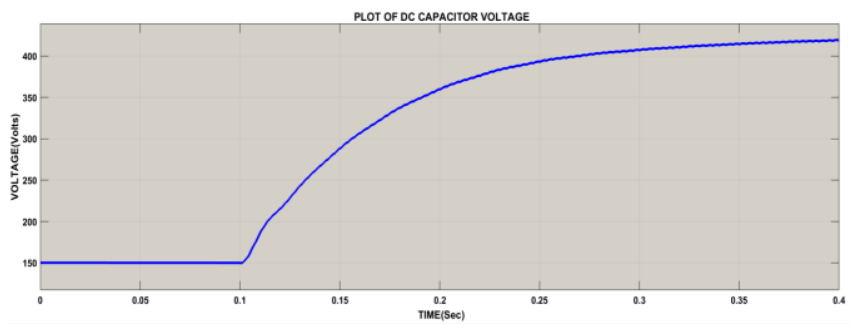

Figure 9: Simulation result DC capacitor voltage

Figure $10-12$ shows the FFT Waveform of the generated source current. The simulation performed with controller parameters optimized for ITAE, IAE, and ISE performance indices are shown

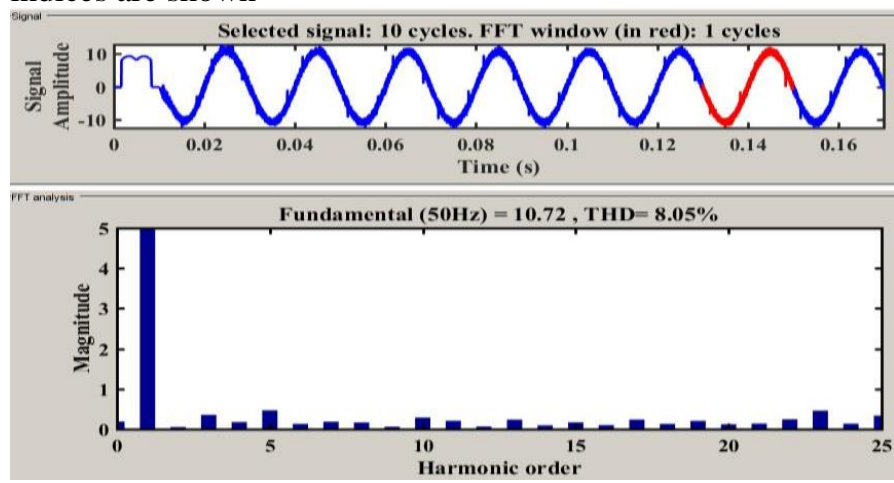

Figure 10: FFT analysis of Source current using Gravitational Search (IAE Criteria)
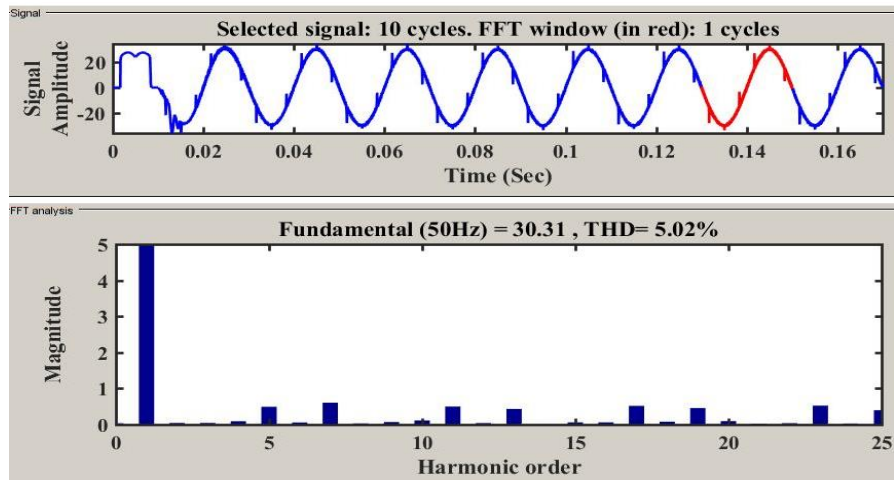

Figure 11: FFT analysis of Source current using Gravitational Search (ITAE Criteria) 


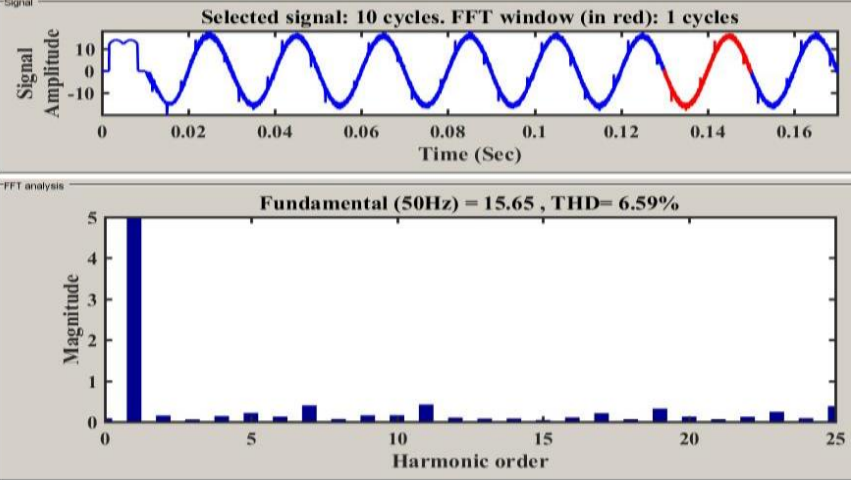

Fig 12:- FFT analysis of Source current using Gravitational Search (ISE Criteria)

In this section results obtained by using Gravitational Search Algorithm (GSA) are described. Gravitational Search Algorithm is used for the optimization of PI controller which tries to reduce the Total Harmonic Distortion in the source current.

In Fig 11 FFT analysis of source current using Gravitational Search (ITAE Criteria)is represented. It is seen that the THD value is $5.02 \%$ which less than the value of THD as in case of Gravitational Search (IAE Criteria) and Gravitational Search (ITAE Criteria)

In Fig 10 and fig 12 FFT analysis of source current using Gravitational Search (IAE Criteria and ITAE) is represented. It is seen that the THD value is $6.59 \%$ which is less than the value of THD as in case of Gravitational Search (IAE Criteria) but greater than the value of THD in the case of Gravitational Search (ISE Criteria).

Table 1

\begin{tabular}{|c|c|c|c|}
\hline CSA Parameter & IAE & ISE & ITAE \\
\hline P & 615.36 & 426.32 & 372.65 \\
\hline I & 352.35 & 376.19 & 452.47 \\
\hline Kp & 425.29 & 258.32 & 232.32 \\
\hline Ki & 185.52 & 117.14 & 114.35 \\
\hline $\begin{array}{c}\text { CURRENT THD } \\
(\%)\end{array}$ & $\mathbf{8 . 0 5}$ & $\mathbf{5 . 0 2}$ & $\mathbf{6 . 5 9}$ \\
\hline \multicolumn{1}{|c}{}
\end{tabular}

In table tuned values of GSA Parameter like ,P,I, $\mathrm{K}_{\mathrm{p}}$ and $\mathrm{K}_{\mathrm{i}}$ are obtained from Gravitational Search Algorithm optimization techniques is represented. From Table. 1 it is clear that the current THD is minimum in the case of ISE criteria as compared to the other criteria i.e IAE and ITAE.Parameters $\mathrm{P}$, $\mathrm{I}, \mathrm{Kp}$ and $\mathrm{Ki}$ are the simulation PI Controller parameter which can be optimized by the help of Gravitational Search Algorithm optimization techniques.

\section{CONCLUSIONS}

The increment of non-linear loads in system has increased to a great extent with the utilization of electronic switches. The increase in non-linear loads causes the percentage THD to increase to a great extent. With the increase in percentage THD the equipment failure problems also increases. The power filters technology has grown widely for the compensation of different types of non-linear loads through current based compensation and for the reduction of voltage harmonics, sags swell and regulation of voltage by voltage based compensation techniques. Hybrid filters proves to be a cost effective solution for the elimination of harmonics or to improve the performance of the system as compared to active and passive filter used alone. The passive filter has the demerits of fixed compensation and resonance which can be overcome by active filters.

The above simulation is performed under three criteria i.e Integral time absolute error(ITAE), Integral square error (ISE) and Integral time square error(ITSE).From Table 1. it is clear that criteria ISE gives minimum THD as compare to ISE and ITAE. Gravitational Search optimization technique is applied to mitigate reactive power and power quality issue.

\section{REFERENCES}

[1] Bhim Singh, Kamal Al-Haddad, Ambrish Chandra “ A Review Of Active Filters For Power Quality Improvement” IEEE Transactions On Industrial Electronics, Volume 46, No. 5, October 1999.

[2] Bhim Singh, Vishal Verma,"An Indirect Current Control Of Hybrid Power Filter For Varying Loads" IEEE Transactions On Power Delivery, Vol. 21, No. 1, January 2006.

[3] HimlyAwad,Math H.J. Bollen, "Power electronics for power quality improvements," Industrial Electronics, 2003. ISIE '03. 2003 IEEE International Symposium on, vol.2, no., pp.1129,1136 vol. 2, 9-11 June 2003 doi: 10.1109/ISIE.2003.1267983.

[4] Reyes S. Herrera and Patricio Salmerón "Instantaneous Reactive Power Theory: A Comparative Evaluation of Different Formulations," IEEE Transactions on Power Delivery, Vol.22, No.1, pp.595,604, Jan. 2007 doi:10.1109/TPWRD.2006.881468.

[5] P. Salmeron and S. P. Litran, "Improvement of the Electric Power Quality Using Series Active and Shunt Passive Filters",IEEE Transactions On Power Delivery, Vol. 25, No. 2, April 2010

[6] K. Dharageshwari,C. Nayanatara,'Power Quality Improvement Using Hybrid Filters for the Integration of Hybrid Distributed Generation to the Grid",International Journal of Science and Research (IJSR) ISSN (Online): 2319-7064, Volume 4 Issue 2, February 2015

[7] An Luo, ZhikangShuai, Wenji Zhu, Ruixiang Fan, and ChunmingTu," Development of Hybrid Active Power Filter Based on the Adaptive Fuzzy Dividing Frequency-Control Method", IEEE Transactions On Power Delivery, Vol. 24, No. 1, January 2009.

[8] Fang ZhengPeng, Hirofumi Akagi, and Akira Nabae ,"A new approach to harmonic compensation in power systems - a combined system of shunt passive and series active filters",IEEE Transactions on Industry Applications,Vol. 26. No. 6. November/December 1990.

[9] ToshihikoTanaka, and Hirofumi Akagi, "A new combined system of series active and shunt passive filters aiming at harmonic compensationfor large capacity thyristor converters",Proceedings of IEEE IECON'91, pp. 723-728,1991.

[10] F.Z.PengH.AkagiA.Nabae," Compensation characteristics of the combined system of shunt passive and series active filters"IEEE Transactions on Industry Applications, 1993.

[11] S.-J.Huang and J.-C.Wu,'Design and operation of cascaded active power filters for the reduction of harmonic distortions in a power system",IEEE Proceedings - Generation, Transmission and Distribution, 1999.

[12] Wei-Fu Su , Chin E. Lin, Ching-Lien Huang," Hybrid filter application for power quality improvement", Electric Power Systems Research, 1998.

[13] S.-J.Huang, J.-C.Wu, H.-L. Jou," Electric-power-quality improvement using parallel active-power conditioners",IEE Proceedings - Generation, Transmission and Distribution, 1998. 